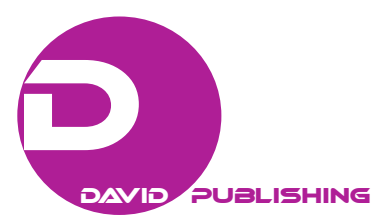

\title{
Strategies for Successful Ageing Living Alone
}

\author{
Boontip Siritarungsri \\ Sukhothai Thammathirat Open University, \\ Nonthaburi, Thailand
}

\author{
Songsri Soranastaporn \\ Mahidol University, Nakhonpathom, Thailand
}

\author{
Malee Surachet \\ Sukhothai Thammathirat Open \\ University, Nonthaburi, Thailand
}

\author{
Karen Francis \\ Australian Catholic University, \\ Ballarat, Australia
}

\author{
Jane Mills \\ James Cook University, Townsville, \\ Australia
}

The purpose of this qualitative study, conducted in Thailand, was to identify strategies for older adults to live alone happily, with dignity, security, and independence. Purposive sampling techniques were used to recruit participants from 12 provinces throughout Thailand. The sample included three groups: older Thai people living alone $(\mathrm{n}=$ 1,087), clinician who working with Thai older adults $(n=149)$, and administrators working in aged care and support services in Thailand $(\mathrm{n}=83)$. Data were collected using structured interview guides. Content analysis was used to identify and develop the study findings. Most of the older Thai people living alone were single, widowed or divorced with few wanting to remain living alone. The large majority of participants needed government assistance to manage their activities of daily living including access to health and public services. Participants wanted aged care and support services to assist with their living arrangements, organise community activities, and provide home visits. Moreover, they wanted their families to visit them and provide financial support and care for them when they were ill. These older adults experienced living alone positively and negatively. Some participants felt proud, dignified, and independent. Other participants felt that living alone resulted in poorer health status, particularly emotional problems, especially for those who were not living alone by choice. These participants reported feeling lonely, bored, irritated, sad, and sorrowful. This group of older Thai adults had limited interaction with their families and the wider community. From this study, four strategies were identified to assist older Thai adults to live alone happily, safely and with a sense of dignity, security, and value. These strategies are: ensuring individual choice, maintaining family support, developing community value, and advocating for over-arching government policy support of aged care. A high number of older adults live alone in Thailand and this presents a big challenge for both these individuals and the community in which they live. If this important group in Thai society is to live alone happily and successfully, it needs to be additional assistance to ensure they are supported by families, communities, and government departments.

Keywords: strategies, successful ageing, independent living, older adult

\footnotetext{
* Acknowledgement: The authors would like to sincerely thank to Sukhothai Thammathirat Open University for financial support of this research.

Boontip Siritarungsri, associate professor, School of Nursing, Sukhothai Thammathirat Open University.

Songsri Soranastaporn, associate professor, Faculty of Liberal Art, Mahidol University.

Malee Surachet, associate professor, School of Law, Sukhothai Thammathirat Open University.

Karen Francis, professor, a joint chair with St. John of God Health Care based in Ballarat, Victoria.

Jane Mills, professor, Centre for Nursing and Midwifery Research, James Cook University.
} 


\section{Introduction}

The world's population in the 21st Century is an ageing society. The proportion of people aged 60 and older will continue to increase, whereas the proportion of child and teenage populations will decrease ${ }^{1}$. By 2050 , it is projected that the world's population will be 9,000 million with older adults aged over 60 accounting for 2,000 million of that population (22\%) (Blackburn, 2009). The United Nations ${ }^{2}$ reported that the number of persons globally aged 60 or over is expected to more than triple by 2100, increasing from 841 million in 2013 to two billion in 2050 and close to three billion in 2100 . Furthermore, already 66 percent of the world's older persons live in the less developed regions and by 2050, 79 percent will do so. By 2100 , this figure will reach 85 percent.

In 2008, the United Nations ${ }^{3}$ projected that the world birth rate would decrease from 2.6 (in 2008) to two (in 2050). The United Nations also reported that the average life expectancy in developed countries would be 78 -years by 2050 and 69 -years for people living in developing countries. Now, more than ever, it is important to consider the steps needed to properly manage and care for older adults to ensure that this group is independent. Independent older adults supported to care for themselves will minimise the burden of care and associated costs on families, communities, and government.

Most older adults in Asia and Latin America live with their children (75\%) whereas the equivalent group in Europe, Australia, and North America live alone (70\%) (Blackburn, 2009). The proportion of older Thai adults has increased continuously from five percent in 1950 to 10.1 percent in 2000 (Chareonwongsak, 2008) and 11.9 percent in $2010^{4}$. In 2007, News Report Office (News Bureau of Public Relations Department, 2007) suggested that this group accounted for 10.7 percent of the population and about 31 percent of these people live alone. A study (Chayovan, 2008) into the living conditions of older adults in Thailand between 1980 and 2007 found that the percentage who live alone is increasing.

For the purpose of this paper, the phrase "successful aging or independent elderly" will be used to refer to older adults who have good physical and mental health. They competently look after themselves and are able to adjust to changes. They do good things for themselves and for others. They have financial security and may also be able to support others (Rowe, \& Kahn, 1987; 2000; Volz, 2010; Young, Frick, \& Phelan, 2007). These independent elderly living alone will have a sense of self-worth and dignity. They have the means and ability to live with happiness and security on their own.

In 1991, the United Nation delivered an ageing policy including five key categories: (1) independence, (2) participation, (3) care, (4) self-fulfillment, and (5) dignity. The challenge for Thai society is to plan for the management of an ageing population who is increasingly living alone, whether by choice or necessity. It is imperative that support structures should be put in place to allow for older adults to independently live alone. Most of the ageing poor in Thailand have a hard life. The Thai government could, by providing adequate and appropriate social welfare, make life easier for this group. Government policy must be aligned with the needs

\footnotetext{
${ }^{1}$ World population prospects: The 2012 revision. Highlights and Advance Tables Working Paper No. ESA/P/WP.228. C2012 (cited 8 September 2013). Available from http://esa.un.org/unpd/wpp/Documentation/pdf/WPP2012_HIGHLIGHTS.pdf

2 United Nations, Department of Economic and Social Affairs, Population Division. World population prospects: The 2012 revision. Highlights and Advance Tables Working Paper No. ESA/P/WP.228. C2013 (cited 2013 September 8). Available from http://esa.un.org/unpd/wpp/Documentation/pdf/WPP2012_HIGHLIGHTS.pdf

3 United Nations. United Nation Statistics Division. C2008 (cited 2011 January 30). Available from http://unstats.un.org

4 Annual report. Thailand aging situation in 2010. Bangkok, TQP Co. LTD. C2010 (cited 2014 January 1). Available from http://www.oppo.opp.go.th/info/Report_OlderSituation53-TH.pdf
} 
of an increasingly ageing population that is more likely than previous generations to be living alone in the later years of life. If these steps are not taken soon, more ageing Thai people will live harder because of chronic diseases and disability (Tapwong, Surachate, \& Siritharungsri, 2007).

A literature review has shown that few studies on ageing and living alone have been conducted in Thailand. It is crucial to study the ways independent older adults are living alone successfully in this country. This study has involved participants from all over Thailand as well as those people who are working with this group. Data has been collected from targetted sample groups to ensure variation in the final data set ensuring findings specific to the total population studied (Duhl, 2005). The study sought to find out why independent older adults were living alone, what they needed to live alone happily and successfully and to identify strategies for strengthening support. These strategies can be turned into guidelines for older adults to lead a productive, fulfilling life. Also, policy makers and organizations that provide aged care and support can use the results to plan and develop services to help independent older adults to live alone happily in Thailand and in the wider international community. Finally, this study will provide data about the population need of this group that can be used in future planning.

\section{Objectives}

(1) To study the reasons why Thai older adults living alone;

(2) To explore needs and wants of Thai older adults living alone;

(3) To analyze the effects of living alone on Thai older adults;

(4) To develop strategies to promote Thai older adults experiencing happiness, a sense of self-worth, dignity, and security while living alone.

\section{Methodology}

This study employed a qualitative research design that included structured interviews that were analysed using a content analysis method. Three groups were recruited to the study:

(1) Thai older adults who live alone $(\mathrm{n}=1,087)$;

(2) clinicians caring for Thai older adults who live alone $(\mathrm{n}=149)$;

(3) administrators working in aged care and support services in Thailand $(n=83)$.

Inclusion criteria for group 1 were that they were Thai older adults aged over 60 years, who live along during the day or the night, or over a 24 hour period. Participants also needed to live in 12 provinces (in five regions, north, south, east, northeast, and central) of Thailand: Lumpang, Sukhothai, Nakornsawan, Ubonrajathani, Udorn, Chantaburi, Nakornnayok, Petchburi, Nakornsrithamaraj, Yala, Pattane, and Narathiwat.

Group 2 participants were clinicians who worked in aged care for eight organizations and who were responsible for with Thai older adults. Inclusion criteria for these participants were that they worked for one of the following organisations.

Group 3 participants were administrators who were responsible for Thai older adults and support services and who worked in one of the following Thai Government organizations: Ministry of Public Health, Ministry of Education, Ministry of Social Development and Human Security, Ministry of Labor, Ministry of Culture, Ministry of the Transportation, Ministry of Defense, and National Health Security Office.

Interview protocols were developed for each of the participant groups recruited to this study. Each interview protocol was tested for face validity with three people from expertise in elderly. The interview 
protocols were amended based on feedback on the clarity and meaningfulness of the questions asked. A pilot study was conducted to further field test the interview protocols with each of the participant groups.

Thirty three experienced university-based research assistants in each province collected and analysed the data for this study. The assistants were given training that included a description of the project, background information about ageing and older adults living alone and interviewing skills and techniques. These research assistants had the chance to practise interview techniques before going into the field. They also were trained to collect, verify, and analyze data using methods of content analysis.

Research assistants conducted interviews individually with participants in their homes or at appointed places. The interviews were recorded of group 1 participants who consented and were taken for use in presentations of the study.

Each interview was transcribed for subsequent analysis. The researchers verified the interview data before a content analysis of all the data was undertaken. First, qualitative data were grouped and frequencies counted. Next, percentages were calculated for these data and, finally, data were synthesized according to the research objectives (Hsieh \& Shannon, 2005).

\section{Research Findings}

Findings were grouped into four categories each of which aligns with one of the objectives of the study. These four categories are: reasons for living alone, needs of older adults living alone, effects of living alone, and strategies to assist older adults to live alone independently. A number of sub-categories were applied to data in the final "strategies" category.

(1) Reasons why older adults live alone: Group 1 participants lived alone during the day because family members with whom they were living had to go to work or were studying outside the home $(40.23 \%)$. The major reason why older adults lived alone, 24 hours a day $(59.77 \%)$ was that their spouse or children had died (15.28\%). Participants, however, reported that they lived alone because their family neglected them $(9.92 \%)$, and they had no living relatives, respectively ( $8.93 \%)$, while some aged people lived alone by choice $(6.55 \%)$.

(2) Needs and wants of ageing people who live alone: Older adults who live alone most frequently spoke of wanting government support. They also spoke of needing help from communities and family. Most group 1 participants received financial support from the government (77.29\%) to subsidise their living and health care costs. This group also reported spending money on medical aid devices such as wheel chairs, eye glasses, walking sticks, or crutches (37.79\%), which created a financial burden for them. Older adults wanted services from communities such as accommodation and necessary things for their daily living (29.87\%) and recreation activities $(20.76 \%)$. Group 1 participants in particular wanted their family members to visit, to take them on excursions to interesting places $(39.04 \%)$ or to give them financial support $(22.52 \%)$.

(3) The effects of living alone on ageing people: The results of data analysis showed three views of living alone held by ageing people: positive (36.01\%), negative (33.91\%), and neutral (30.08\%). The first group said that they were proud to live alone and were happy and ageing with dignity because they did not burden anyone with their care. The second group said they felt unhappy, lonely, and bored. Some people expressed a wish to die because living was difficult, and they had chronic diseases or no one to take care of them. The last group, which had neutral feelings about ageing alone, prepared themselves well to live alone and were relatively content with their situations. 
(4) Strategies of ageing to live alone happily, valuablely, dignifiedly, securely: Four strategies were identified by all three groups of participants to support ageing people to live alone happily and securely with a sense of worth and dignity.

\section{Individual Strategies}

Ageing people expressed that preparation was one of the key ways to live well into old age. People who worked hard and collected money and property for economic security were the most contented group. They took care themselves well and they were healthy in both mind and body. Some people also took care of their families and were volunteers as well as being good models for their families. These jobs and responsibilities helped them to feel valued and gave them a sense of self-worth. These strategies, applied by individuals, were similar across all regions.

\section{Family Strategies}

Many ageing people stated that they wanted their kids to take care of them, visit them, telephone them, or give them money. They said that this was part of Thai culture and tradition. If children regarded their elders as important, the elders felt valued and had dignity.

\section{Community or Local Organization Strategies}

Ageing people wanted their community or local organizations to provide an environment and arrange services that would help them to live alone. They believed that ageing funds should be established so elderly people could receive help as soon as they needed it. Government administrators suggested that training programs or activities which were useful for ageing people played a significant role in giving meaning and purpose to the lives of older people. Government and non-government organizations can provide these training programs or activities which promote health, religion, education, and culture. The examples of training programs or activities were as follows: recreation, travelling, religion practice, exercises, occupation training, hobbies, using the Internet, and learning new things. These training programs or activities were considered as important factors which enhanced ageing people to live alone happily, securely, and with a sense of value and dignity.

\section{Government Strategies}

Participants stated that there are eight organisations that have responsiblility for aging people, however, there is a lack of coordination among the organisations. They commented that if these organisations worked together, aging persons would benefit. According to The Act on the Elderly ${ }^{5}$ (B. E. 2546 or 2003 A. D.), the government needs to invest in implementing the Act. The Thai government introduced an Act, Session 11 that states, all Thai elderly have the right to access health promotion, protection, and support services including medical and public health services, education, religion, appropriate occupation, and provision of advice and consultation on other proceedings in connection with a case or to remedy of family problems. Unfortunately many aged persons have not been able to access to the range of services outlined in this legislation. Improving access can be achieved if additional funding is allocated to meet the health and welfare needs of elderly Thai people. Currently, the Thai Government distributes funding to local administrators at the Community Municipality Level in each province but it is insufficient. To supplement funding provided by the Government, local organisations are required to fund raise and seek additional support from private enterprise if priority initiatives are to be realized to improve the health and wellbeing of elderly Thai people.

5 The Act on the Elderly B. E. $2546 \quad(2003$ A. D.) (cited 2014 January 10). Available from http://www.oppo.opp.go.th/info/pororborENG_2003 (UP11072013).pdf 


\section{Discussion}

The discussion will be structured around the research questions.

(1) Reasons for ageing to live alone: The number of elderly people living alone is increasing, especially those ageing people who are living alone 24 hours a day (59.77\% of those surveyed). The findings of this study that more people are living alone by necessity rather than choice - conform with the findings of Jitapunkul (2000) who found that most elders in Thailand lived alone because they had been widowed, had outlived their children or their children had moved away from them for work reasons. Almost 10 percent of Jitpunkul's (2000) study participants lived alone 24 hours a day because their families neglected them. Chayowan (2008) surveyed the ageing situation in Thailand between 1980 and 2007 and found that the number of elders living alone had increased continuously and some of these elderly people were neglected. Consequently, they faced problems and difficulties in terms of health and expenses because most of the ageing people did not have property. Rubkhomdee et al. (2007) found that elders lived alone more often now because Thai families were using a "nuclear family" model instead of an extended family model. Television news on Thai Channel 3 on July 19, 2009, reported that elders aged 100 and 109 were neglected and forced to live alone. Finally, their neighborhood and government organizations had to step in to provide help because these two elders had poor health, no money and were suffering from grief. These problems reflect a deterioration of Thai culture and tradition in which children are now seen as ungrateful to their parents and irresponsible.

This study also revealed that the many Thai elders have had limited formal education, most having left school at the primary school level. Thai elders in this study were mostly aged older than 70 years $(60 \%)$. Very few Thai people of their generation (5.54\%) went to secondary school, even less studied at a university level. Previous studies have found that education level has minimal impact on the strategies employed by elderly people living alone. A study titled "Factors associated with the successful aging of the socially-active elderly in the metropolitan region of Porto Alegre" conducted in the Metropolitan Region of Porto Alegre (João Feliz, Duarte de Moraes, \& Valdemarina Bidone de Azevedo e Souza, 2005) found that elders who had different levels of education did not employ different strategies to live alone successfully. This finding is significant because it means that strategies identified in this study may be equally applied to a number of demographics and socio-economic groups in Thailand.

(2) Needs and wants of ageing people who live alone: This study found that ageing people who live alone often require financial support from the government and access to funded health care. Most of the ageing population in this study did not save money and acquire property when they were young, so they had few possessions if any when they were older. As a result, their children or relatives were more likely to neglect them. Rubkhomdee et al. (2007) also found a correlation between the wealth of elderly people and the likelihood that they would be neglected or forced to live alone. Elderly people who were in a strong financial position were more likely to be cared for or the subject of concern to their children and relatives. If elders did not have money, they were more likely to be neglected. In Rubkhomdee et al.'s (2007) study, just $52.4 \%$ of elders were well-prepared in terms of finance. This reflects a social value being seen more often in Thai people that says that money is very important, and that money can buy even happiness. Therefore, it is important to people to save money and acquire property. Jitapunkul (2000) also found that a secure financial position was important to maintain a high quality of life in old age. Not all people, however, can establish financial security, so the Thai government needs to consider encouraging people to save money and establish village funds for ageing. 
A healthy lifestyle is also important to aged people, but the focus on health needs to begin at a far younger age. The older people get, the greater the likelihood they will suffer from illness or disease. Nukulkit, Ponpaipan, and Triamchaisri (2002) found that elders in Thailand who were supported by health care teams to take care of their wellbeing could also take care of themselves more successfully. Jitipunkul (2000) proposed to the Thai government that it established health security for Thai people to enable them to live healthy and independent lives. Presently, health promotion campaigns are being given a high priority. These health promotion policies should be applied into real practice to all Thai groups, so they will prepare themselves well to be successful, strong, and healthy later in life. However, some Thai people prefer to consume too much food instead of eating a healthy amount of appropriate food. Thai people need to consider the future and take care of their health by eating appropriate food, having enough rest, and leading their life by using Sufficiency Economy Theory. King Rama initiated the Sufficiency Economy Theory which is based on the fundamental principles of Thai culture. It is a method of development based on moderation, prudence, and social immunity, one that uses knowledge and virtue as guidelines in living. Significantly, there must be intelligence and perseverance which will lead to real happiness in leading one's life $^{6}$.

Some ageing people who live alone wanted greater help and support from their families. They wanted their family members to stay in telephone contact, to visit them or to take them on trips. Ageing people also expressed a desire for family members to take them to see doctors when they were sick. Ageing Thai people need their families but the trend towards a nuclear family structure is leading to greater numbers of older people being forced to take care of themselves. Thus, a campaign to encourage children to take care of their parents needs to be carried out at all levels in Thailand: individual, family, and society. This campaign may also focus on technology and the ways children may use mobile phones or the Internet to communicate with their parents to lessen their loneliness.

Some ageing people were proud to live alone and said that they were happy because they did not place a burden on anyone else's shoulders. They had dignity in old age because they prepared themselves well for the future. However, the proportion of people in this group $(6.55 \%)$ is smaller than those who did not prepare themselves well (33.91\%). Thai government should plan to increase number of people who feel well-prepared for the future.

(3) The effects of living alone on ageing people: Ageing people who live alone face more problems and difficulties than those who live with others. Older people who lived alone were more likely to have health problems or chronic diseases such as diabetes mellitus, hypertension, bone and muscular diseases. Consequently, they wanted more money from the government. Ageing people did not have to pay for health care costs but they did struggle to meet the associated costs of travelling to see doctors. Travelling alone also presented problems for some participants; they needed help. Family Development Institute ${ }^{7}$ and a research (Ratana-Ubol et al., 2009) affirm that elderly people who prepared well for the future had fewer problems and difficulties than those who did not.

Moreover, the results of data analysis in the present study showed that ageing people who put little

\footnotetext{
6 Chaipattana Foundation. Philosophy of Sufficiency. C2013 (cited 2013 November 8). Available from http://www.chaipat.or.th/chaipat_english/index.php?option=com_content\&view= article\&id=4103\&Itemid=293

Plans and Policies of the Family Development Institute. C1998 (cited 2001 January 2). Available from http://www.women-family.go.th/family/document.pdf
} 
thought or planning into their later life, and who were living alone and neglected, were more likely to experience apathy towards life or suicidal thoughts. These results align with Plans and Policies of the Family Development Institute ${ }^{21}$, which showed psychological problems affected individually number of people who had no choice but to live alone in old age. At a country level, the medical cost both for out-patients and admitted patients was significant for this group. The Family Development Institute study (1998) showed that a number of ageing people who live alone 24 hours a day (7.63\%) had severe psychology symptoms such as boredom, depression, grief, and suicidal thoughts. Some ageing people in this group committed suicide. Prevention of such an outcome is important.

(4) Strategies for ageing people to live alone happily, securely and with a sense of self-worth and dignity: Strategies are discussed below to manage the needs of an increasing sector of world society-ageing people who live alone. Action needs to be taken on four levels: individual, family, community, and country. If elderly people are to live happy, secure lives with a sense of worth and dignity, they need to have financial security, sound health and well being, community support, and the protection of government policy. Wider policy issues, such as birth control and protection of the rights of older people, also need to be considered to deal with the world's ageing population.

\section{Financial Security}

One of the most important factors to maintaining independence and happiness in old age is financial security (Depp \& Jeste, 2006). Dorris (n.d.) also stated that ageing people who live successfully are those people who had financial security because they planned and managed their finances well. Mohd's research in Malaysia (Mohd Saidatulakmal, 2013) suggested that cooperatives for workers should encourage the workers to save through their cooperatives. Further, the role of the cooperatives could be expanded to include managing members' savings for retirement. Finally, the cooperatives could be put under the Ministry of Entrepreneur and Cooperative Development to monitor the activities and take charge in investing and safe guarding the members' savings.

People need to be taught how to plan their budgets and economic needs to span a life time. This includes advice and guidance about planning for risk, contingency, and change. The message to people of all ages is that you need to work hard, live economically, and save money for the future. Taking these financial steps helps people to maintain their dignity because they are independent. The Thai government does allocate money to ageing people but older people who are living alone with chronic diseases may still find it difficult to meet their financial needs. This situation is similar in Japan where the number of ageing people living alone continues to increase. This group receives a limited amount of money and lives difficult and often poverty-stricken lives, according to Fukue (2010) reported in The Japan Times. The policy of the Japanese government in this matter is to increase the numbers of nursing homes and services. Blackburn (2009) proposed a global pension plan for ageing people. This plan if acted on may assist elderly people care for themselves and remain independent. If the Thai Government established an ageing fund or introduced an ageing tax this plan could be realised. These types of policies have been introduced in a number of countries, for examples $\operatorname{Japan}^{8}$ and Germany (Jackson, 2003).

\footnotetext{
${ }^{8}$ South China Morning Post Economy. Japan braces for era of higher taxes as costs of ageing society rise. C2014 (cited 2014 June 13). Available from http://www.scmp.com/business/economy/article/1461887/japan-braces-era-higher-taxes-costs-ageing-society-rise
} 


\section{Health and Wellbeing}

Promotion and policy need to focus on health and wellbeing and these messages need to be targeted towards people of all ages - not simply the elderly. People who think about their health only in old age may find they have left it too late to stave off illness or prevent disease. People need be encouraged to eat appropriate healthy food, exercise, and take care of their emotions and minds. People also need to see doctors regularly and to follow up any recommendations promptly to detect diseases and problem areas early. Elderly people are more likely than younger people to be sick, but this increased risk may be mitigated by healthy living earlier in life. This study also highlights the importance of sound mental health. Ouwehand, de Ridder, and Bensing (2006) concluded that proactive coping and attempting to prevent potential stressors, may be a valuable strategy for successful aging and contribute to well-being. Elders who are able to accept and adapt to change are healthier in body and mind. If elderly people engage in healthy behaviours and activities, they can also contribute to the general wellbeing of their communities by being good role models. This positive role model behavior is important because elders can transfer their knowledge and experiences to young people. In this way, elderly people can also maintain a sense of self-worth by strengthening healthy attitudes in their communities.

\section{Support Services for the Elderly}

Elderly people need facilities and services to support independent living and personal growth into old age. These services can enhance quality of life for older people. Tsai et al. (2007) studied ageing populations in Taiwan and found that elderly people who felt supported and cared for by local community groups and organizations were happier and more confident in their ability to live independently. Tsai et al. (2007) recommended Governments and community agencies foster supportive communities that encourage people to plan daily living needs, that resources and services such as, personal mobility, wheel chair, are provided locally in communities, and that elderly people have opportunities to participate in community activities

\section{Government Policy Protection}

People are living longer lives than ever before. Advances in medical knowledge and technology are leading to ever-increasing life expectancies. Demographics are changing all over the world. Governments also need to change policies and practices to meet the changing needs of their countries. A research of Tsai et al. (2007), for example, concluded that the short-term policies for promoting successful aging in Taiwan should focus on health status and life style. In the long run, the local governments should improve the external factors through revolution of the system and social education. For in Thailand, the Elderly Act 2003 should firstly be implemented the short term and long term plan that covered health status and life style because it is clearly stated in terms of rights and benefits of ageing but some government organizations did not implement the act to their practice totally.

Governments and communities must also consider the ways they can mitigate the side effects arising from changes in Thai culture and society. Historically, Thai people have lived in extended families with several generations sharing homes and responsibilities. In more recent years, Thai people are more likely to be living in nuclear families or living alone. People are increasingly neglected by their families in this new community structure (Podhisita, 2011). Researchers in this study recommend that the government promoted and incentivized caring of aged family members.

Ageing people will be able to live alone successfully only if action is taken at all levels of society. Supporting Thailand's ageing population must be a priority for individuals, families, communities, and 
governments. Strategies for living a healthy, strong, useful life in later life should be applied together with the sustainable philosophy of His Majesty King Bhumibol Adulyadej who stated "Health is resulted from good society" . This sustainable philosophy applies to healthy ageing and incorporates independent living, health promotion, and security. Jitapunkul, Chayovan, and Kespichayawattana (2002) proposed that the Thai government establishes a long-term plan and that all levels of society need to participate systematically to set up a system that supports an ageing population. Problems faced by ageing people who live alone have an impact on the whole of society-economically and socially.

\section{Recommendations}

A number of recommendations for nursing education, research directions, ageing populations are offered. All pre-service nursing programs should include curriculum content related to aged care and management. Continuing professional development programs may be developed for the nursing workforce on ageing and caring for the aged.

Further research needs to be focused in the following areas:

(1) Basic research should include a database of elders who live alone and a study into the living situation of elders-both retired and working.

(2) Applied research needs to be conducted into the readiness of elderly people to live alone.

(3) Research and development needs to focus on the development of a working service model that could be applied in communities across Thailand to support elderly people living alone.

Education opportunities need to be created for elderly people and families in general:

(1) Providing short course training for family members about the health and rights of elderly people and preparing elderly people to live alone happily and independently.

(2) Establishing elders study centres in education institutes study elders to live alone so both knowledge and activities can be used to develop the dignity of ageing. The center may include interdisciplinary.

The results of this study should be incorporated into ageing policy at a country level. Already-established national committees into ageing, chaired by the Prime Minister, need to include strategies for ageing people to live alone happily and independently.

\section{Conclusion}

From this research, four strategies that consist of individual, family, community, and government were identified to assist older Thai adults to live alone happily, safely and with a sense of dignity, security, and value. To ensure individual choice, maintaining family support, developing community value and advocating for over-arching government policy support of aged care, firstly, Thai people need to prepare himself/herself to be healthy life and financial security when they were young. Secondly, family needs to support their parents, both mental and physical supports. Thirdly, community supports daily activities and builds aging networking. Lastly, government has to aging policy and plan, short term and long term to support individual, family, and community activities. However, to meet successful aging living alone, strategies have to work together.

\footnotetext{
9 Plans and Policies of the Family Development Institute. C1998 (cited 2001 January 2). Available from http://www.women-family.go.th/family/document.pdf
} 


\section{References}

Blackburn, R. A. (2009). Global Pension Plan 2007. Available from http://www.newleftreview.org/?view=2688

Chareonwongsak, K. (2008). Aging society. Upgrade Education Magazine. Vol. 2 No. 092 (31 July-August).

Chayovan, N. (2008). The elderly situation in Thailand. In Workshop of The Development of Projects for Local Elderly Based on National Plan for the Elderly 2008. Ayutthaya: Ayutthaya Krungsri River hotel Ayutthaya.

Depp, C. A. \& Jeste, D. V. (2006). The definition and predictors of successful ageing: A comprehensive literature review. American Journal of Geriatric Psychiatry, 14(1), 6-20.

Dorris (n.d.). (cited 2014 January 10). Dorris is 80 years old. Available from http://cas.umkc.edu/casww/sa/DorrisStory.htm

Duhl, L. J. (2005). Speaker's corner aging by one who is aging. Journal of Epidemiology Community Health, 59, 816-817.

Fukue, N. (2010). Elderly living alone increasingly dying the same way sign of an aging, isolated society: Lack of family, government support. Available from http://www.japantimes.co.jp/news/2010/07/21/national/elderly-living-alone-increasingly-dying-the-same-way/

Hsieh, H-F, \& Shannon, S. E. (2005). Three approaches to qualitative content analysis. Qualitative Health Research, 15, $1277-1288$.

Jackson, R. (2003). Germany and the challenge of global aging. Center for Strategic and International Studies and Nationwide Global. Available from http://baltichealthcapitalfundation.eu/assets/Knowledge-center/Aging-society/germany-report.pdf

Jitapunkul, S. (2000). Experiences and suggestions of integrated services to the elderly in the community. Journal of Gerontology and Geriatric Medicine, 1(2), 67-79.

Jitapunkul, S., Chayovan, N., \& Kespichayawattana, J. (2002). National policies on ageing and long-term care provision for older persons in Thailand. In D. R. Phillips \& Alfred C. M. Chan (eds.), Ageing and long-term care national policies in the Asia-Pacific. Singapore: Institute of Southeast Asian Studies.

João Feliz, Duarte de Moraes, \& Valdemarina Bidone de Azevedo e Souza. (2005). Factors associated with the successful aging of the socially-active elderly in the metropolitan region of Porto Alegre. Available from http://www.scielo.br/scielo.php?pid=S1516-44462005000400009\&script=sci_arttext

Mohd Saidatulakmal (2013). Old age financial security of the informal sector. The 2013 WEI International Academic Conference Proceedings Orlando, USA School of Social Sciences. Penang: Universiti Sains Malaysia.

Nukulkit, P., Phonphaiphan, M., \& Triamchaisri, S. (2002). Factors associated with successful holistic health of Thai elderly. Journal of Gerontology and Geriatric Medicine, 3, 3-19.

Ouwehand, C., de Ridder, D. T. D., \& Bensing, J. M. (2006). A review of successful aging models: Proposing proactive coping as an important additional strategy. Clinical Psychology Review, 27, 873-884.

Podhisita, C. (2011). Thai family and household changes: What we don't know. Available from http://www2.ipsr.mahidol.ac.th/ConferenceVII/Download/2011-Article-02.pdf

Ratana-Ubol, R. et al. (2009). The study of State, problems, needs, and non-formal education and informal education models to enhance learning for preparation of Thai labour when entering to the elderly age (research paper). Available from https://www.academia.edu

Rowe, J. W., \& Kahn, R. L. (1987). Human ageing: Usual and successful. Science, 237(4811), 143-149.

Rowe, J. W., \& Kahn, R. L. (2000). Successful ageing. New York: Random House.

Rubkhomdee, V., Rubkhomdee, S., Nammaeng, A., \& Wanpontong, T. (2007). A project of survey risk of Thai family. Cooperation between Center of Surveillance and Social Warning, Office of the Permanent Secretary, Ministry of Social Development and Human Security, and School of Social and Environmental Development, National Institute of Development Administration. Available from http://surveillance.m-society.go.th/news-detail-2.html

Tapwong, J., Surachate, M., \& Siritharungsri, B. (2007). The guidelines for technology and facility service arrangement for disabled people and elderly in Thailand. NECTEC report.

Tsai, C-Y, Hsu, Hui-Chuan, Chang, Ming-Cheng, \& Luh, Dih-Ling. (2007). Constructing the community-level successful ageing indicators for the local government in Taiwan. Available from https://apha.confex.com/apha/135am/techprogram/ paper_ 156185.htm 135am/techprogram/ paper_156185.htm

Volz, J. (2010). Successful ageing: The Second 50. Available from http://www.apa.org/monitor/jan00/cs.aspx

Young, Y., Frick, K. D., \& Phelan, A. E. (2007). Can successful ageing and chronic illness coexist in the same individual? A multidimensional concept of successful ageing. Psychology and Ageing, 22(4), 705-718. 